\title{
Medication adherence and its determinants among psychiatric patients in an Ethiopian referral hospital
}

This article was published in the following Dove Press journal:

Patient Preference and Adherence

25 September 2014

Number of times this article has been viewed

\section{Zaid Demoz' \\ Befikadu Legesse ${ }^{1}$ \\ Gebrehiwot Teklay' \\ Birhanu Demeke' \\ Tewodros Eyob ${ }^{2}$ \\ Zewdneh Shewamene ${ }^{3}$ \\ Mubarek Abera ${ }^{4}$ \\ 'Department of Pharmacy, College of Health Sciences, Mekelle University, Mekelle, ${ }^{2}$ Department of Pharmacy, College of Public Health and Medical Sciences, Jimma University, Jimma, ${ }^{3}$ Department of Pharmacology, School of Pharmacy, University of Gondar, Gondar, ${ }^{4}$ Department of Psychiatry, College of Public Health and Medical Sciences, Jimma University, Jimma, Ethiopia}

Background: The degree to which an individual follows medical advice is a major concern in every medical specialty. Non-adherence to psychiatric treatment regimens has a profound impact on the disease course, relapse, future recovery, cost of health care, and the outcome for the patient. The aim of this study was to assess medication adherence and its correlates among psychiatric patients at Ayder Referral Hospital, Northern Ethiopia.

Methods: A cross-sectional study was conducted from June to September 2013 at Ayder Referral Hospital, where 423 patients were selected by a systematic random sampling technique from all patients attending the psychiatric clinic at the hospital. Data were collected by trained data collectors through interview of the patients using a structured questionnaire. The collected data were entered into Epi Info version 7 and analyzed by Statistical Package for the Social Sciences version 16 software. Logistic regression was used to assess independent predictors of adherence.

Results: A total of 387 patients completed the interview. Two hundred and sixteen $(55.8 \%)$ and $113(29.2 \%)$ were patients with a diagnosis of schizophrenia and mood disorder, respectively, while $35(9 \%)$ and $23(5.9 \%)$ had a diagnosis of drug addiction and autistic disorder. Two hundred and seven $(71.6 \%)$ patients were found to be adherent to their medication. When adherence rates were observed according to type of disorder, 60 (53.1\%), 24 (68.6\%), $149(69 \%)$, and $18(78.3 \%)$ of patients with mood disorder, drug addiction, schizophrenia, and autism, respectively, were adherent to their medications. Female gender (adjusted odds ratio [AOR] 2.34; 95\% confidence interval [CI] 1.45-3.74), tertiary education (AOR 2.69; 95\% CI 1.46-4.85), living with family (AOR 2.57; 95\% CI 1.66-4.58), and shorter treatment duration (AOR 1.82; 95\% CI 1.21-2.84) were among the variables associated with better adherence.

Conclusion: Suboptimal adherence was observed among psychiatric patients in this study. Health professionals in the psychiatric clinic and pharmacists need to focus on and counsel patients about adherence and its implications for their clinical outcome.

Keywords: medication adherence, psychiatric patients, Ethiopia

\section{Introduction}

Psychiatric/mental disorders are clinically significant behavioral or psychological syndromes associated with distress or disability and with a significantly increased risk of death, pain, disability, and loss of freedom. In addition, the syndrome must not be merely an expectable and culturally sanctioned response to a particular event. As a result of their high prevalence, early onset and persistence, psychiatric disorders contribute substantially to the burden of illness worldwide. ${ }^{1}$

While considerable progress has been made in the development of psychopharmacological agents to treat patients with psychiatric illness, adherence with
Correspondence: Tewodros Eyob Department of Pharmacy, College of Public Health and Medical Sciences, PO Box 378, Jimma University, Jimma, Ethiopia

Email teda.eyob@gmail.com 
prescribed treatment remains an enormous problem. It is also the single greatest determinant of the effectiveness of psychiatric medication. ${ }^{2,3}$ Adherence to a medication regimen is generally defined as the extent to which patients take medications as prescribed by their health care providers. It includes taking the prescribed number of pills each day and the timing of doses (taking pills within the prescribed period). Non-adherence is a significant problem in all patient populations, from children to the elderly. Adherence rates are typically lower among patients with chronic diseases, as compared with those with acute conditions. This tends to worsen the prognosis of the illness, leading to lifelong treatment. ${ }^{4}$ Medication adherence reported for people with psychiatric illness is in the range of $24 \%-90 \%$ for those treated with antipsychotic medication and $40 \%-90 \%$ for those treated with antidepressants. ${ }^{5}$

Adherence to a medication regimen involves behavioral change on the part of the patient. Compliance and behavioral changes are positively influenced by the patient's level and stability of family support, level of self-awareness about their health status, and the efficacy of treatment. Self-efficacy can also affect motivation and behavior. Patients with a high degree of self-efficacy are more likely to be actively involved in developing and completing tasks related to a medical or treatment regimen. ${ }^{6}$

Over the course of a year, about three quarters of patients prescribed psychotropic medication will discontinue, often coming to the decision themselves and without informing their health care professional. ${ }^{7}$ Most methods for improving adherence to treatment for chronic health problems are complex, labor intensive, and not predictably effective. ${ }^{8}$ Non-adherence to psychiatric medications or treatment regimens has a great influence on the course of psychiatric illness, relapse, and future recovery. In addition, there can be a profound impact on the cost of care, as well as significant impediments to the patient's long-term adaptation, including social, vocational, and academic functioning. ${ }^{9} 10$

Because of its under-resourced health care system, in particular for psychiatric services, medication non-adherence rates in Ethiopia might be potentially much higher, thereby contributing to a substantial worsening of illness, increased mortality, and escalated health care costs. ${ }^{11}$ Improved understanding of the magnitude and underlying reasons for non-adherence would help to design contextually modified strategies. ${ }^{12}$ This study was conducted to assess levels of adherence and its determinants in patients attending a psychiatric clinic in Ethiopia.

\section{Materials and methods Study setting and period}

This cross-sectional study was conducted in the psychiatric clinic at Ayder Referral Hospital, Mekelle City, Northern Ethiopia, from July to September 2013. Based on the 2007 census, the total population of the city is estimated to be about 300,000 . The hospital is the second largest in the country, with a patient flow exceeding 100,000 per year. The hospital has a total bed capacity of 500 in four major departments and other specialty units, along with six other affiliated hospitals in the region.

\section{Study subjects and sampling}

The source population consisted of all psychiatric patients being followed up for at least 6 months in the psychiatric clinic; while the study population comprised only of psychiatric patients who were on the follow-up treatment. Patients who were not interested or seriously ill were excluded from the study.

The sample size was determined using the single population proportion formula, $\left[Z^{*} p^{*}(1-p)\right] / d^{2}$. Since there were no comparable studies in similar settings, the proportion of psychiatric patients adherent to their medication $(p)$ was assumed to be $50 \%$; employing a $Z$-score of 1.96 (at a $95 \%$ confidence interval) with a $5 \%$ degree of precision and by considering a $10 \%$ non-response rate, the final sample size was determined to be 423 . A systematic sampling technique was employed to select the study participants, using the list of patient cards as a sampling frame.

\section{Data collection}

A pretest was done on 22 patients who were excluded from the final sample, and necessary modifications were made to the tools and procedures for data collection. The data were collected by two trained nurses through interview of the patients using a pretested, structured questionnaire adapted from other studies. ${ }^{11}$ Appropriate supervision and spotchecking of the data collection was done by the principal investigator. Adherence was assessed by self-reporting via a structured patient interview focusing on how often regular medication doses were missed altogether, and whether patients missed taking their doses on time.

\section{Data analysis}

The collected data were entered to Epi Info version 7 and analyzed by Statistical Package for the Social Sciences version 16 for Windows software (SPSS Inc., Chicago, IL, USA). A logistic regression test was employed to identify determinants 
of medication adherence among the patients. A $P$-value $<0.05$ was considered to be statistically significant.

The adherence level of each respondent in the month proceeding the data collection period was determined by dividing the number of doses taken by the total number of doses that should have been taken. Patients who took $\geq 80 \%$ of their prescribed medications for the month preceding the data collection were considered to be adherent while those who took $<80 \%$ of the prescribed medications were classified as non-adherent. ${ }^{13,14}$ The percent adherence of individual patients was averaged to obtain the overall percent adherence of the study population.

\section{Ethical clearance}

Ethical approval for the study was obtained from the ethics review committee at Mekelle University. Informed, written consent was taken from each patient prior to commencing the study. The right to withdraw from the study at any point in time was respected. Privacy and strict confidentiality was maintained during the interview process.

\section{Results}

\section{Patient sociodemographic characteristics}

Of the 423 patients eligible to participate in the study, 387 actually completed it, giving a response rate of $91.5 \%$. The remaining 24 patients were considered to be non-respondents; these patients either claimed that they were too busy to be interviewed or provided contradictory and unreliable information because of their acute and severe psychopathology. About half (50.6\%) of the patients were males. The mean (standard deviation) patient age was $43 \pm 5.03$ (range 15-72) years (Table 1).

\section{Patient clinical characteristics}

Of the total respondents, 216 (55.8\%) were schizophrenic, $113(29.2 \%)$ had a mood disorder, 35 (9\%) were drug addicts, and $23(5.9 \%)$ had autism. Most of the patients were taking an antipsychotic only (57.1\%), 20.4\% were taking an antipsychotic and an antidepressant, $16.8 \%$ were taking an antipsychotic and a mood stabilizer, and $5.7 \%$ were on a combination of antipsychotics, antidepressants, and mood stabilizers.

Regarding the number of medications the patients were prescribed with, the majority (70.8\%) of them received one drug; whereas $23.5 \%$ and $5.7 \%$ were taking two and three medications, respectively. Concerning experience of side effects from medications, half (49.6\%) had drowsiness, 18.6\% experienced weight gain, and $31.8 \%$ reported experiencing more than one side effect, such as sexual dysfunction, vomiting, or
Table I Sociodemographic characteristics of study participants

\begin{tabular}{|c|c|c|}
\hline $\begin{array}{l}\text { Sociodemographic } \\
\text { characteristics }\end{array}$ & n ( $\mathbf{N}=\mathbf{3 8 7})$ & Percentage \\
\hline \multicolumn{3}{|l|}{ Age (years) } \\
\hline $15-25$ & 116 & 30.0 \\
\hline $26-35$ & 126 & 32.6 \\
\hline $36-45$ & 96 & 24.8 \\
\hline $46-55$ & 41 & 10.6 \\
\hline $56-75$ & 9 & 2.3 \\
\hline \multicolumn{3}{|l|}{ Sex } \\
\hline Male & 196 & 50.6 \\
\hline Female & 191 & 49.3 \\
\hline \multicolumn{3}{|l|}{ Marital status } \\
\hline Married & 130 & 33.6 \\
\hline Single & 183 & 47.3 \\
\hline Divorced & 22 & 5.7 \\
\hline Widowed & 52 & 13.4 \\
\hline \multicolumn{3}{|l|}{ Religion } \\
\hline Orthodox Christian & 287 & 74.2 \\
\hline Muslim & 96 & 24.8 \\
\hline Protestant & 4 & 1.0 \\
\hline \multicolumn{3}{|l|}{ Educational status } \\
\hline Illiterate & 106 & 27.4 \\
\hline Able to read and write & 16 & 4.1 \\
\hline Primary education & 24 & 6.2 \\
\hline Junior and secondary education & 95 & 24.5 \\
\hline College and above & 146 & 37.7 \\
\hline \multicolumn{3}{|l|}{ Occupation } \\
\hline Merchant & 17 & 4.5 \\
\hline Government employee & 41 & 10.8 \\
\hline NGO employee & 12 & 3.2 \\
\hline Farmer & 83 & 21.8 \\
\hline Housewife/jobless & 106 & 27.9 \\
\hline Student & 121 & 33.8 \\
\hline \multicolumn{3}{|l|}{ Place of residence } \\
\hline Urban & 267 & 69.0 \\
\hline Rural & 120 & 31.0 \\
\hline \multicolumn{3}{|l|}{ Living conditions } \\
\hline Alone & 94 & 24.3 \\
\hline With family & 293 & 75.7 \\
\hline
\end{tabular}

Abbreviation: NGO, non-governmental organization.

restlessness. When asked about the measures they had taken to deal with side effects, $78 \%$ responded that they did nothing, $11.6 \%$ stopped taking their medication, and only $10.4 \%$ consulted a health professional. With regard to psychotropic treatment duration, $195(50.4 \%)$ respondents were on treatment for a mean duration of $17.4 \pm 3.25$ (range 6-24) months.

\section{Medication adherence}

Two hundred and forty-three patients $(62.8 \%)$ reported that they never missed their daily doses and took their medication at the correct time. Two hundred and seventy-seven patients $(71.6 \%)$ took $\geq 80 \%$ of the medications prescribed for the month preceding the data collection period and were 
considered to be adherent, whereas 110 patients $(28.4 \%)$ took $<80 \%$ of their prescribed medications in the month preceding the data collection period, so were considered to be non-adherent. From those who reported missing doses, $70(28.8 \%)$ missed eight or more doses, while the rest missed varying numbers of doses, ranging from one to seven.

When adherence rates were investigated across the types of disorder, 60 (53.1\%) of those with a mood disorder and 24 $(68.6 \%)$ of those with drug addiction were found to be adherent to their medication. In addition, 149 (69\%) of patients with schizophrenia and $18(78.3 \%)$ of those with autism were adherent to their medications (Figure 1).

Feeling better after illness $(51.9 \%)$ and forgetfulness $(21.2 \%)$ were the most common reasons given for missing doses, while side effects of medication, unsatisfactory care from health providers, and pill burden accounted for $17.8 \%, 5.9 \%$, and $1.8 \%$, respectively, of the reasons for non-adherence.

\section{Factors independently associated with medication adherence}

Patient levels of adherence were observed to increase (from $56.0 \%$ to $71.9 \%$ ) with increasing age up to the age of 45 years (see Table 2). Patients in the age range of 26-35 years were found to be significantly more adherent than those aged 15-25 years. Females were twice as adherent as males. Patients with tertiary education were about three times more adherent than illiterate patients, and this difference was statistically significant. Although lower proportions of single, divorced, and widowed patients were adherent to their medications, there was no statistically significant relationship between marital status and adherence level. Government employees were more adherent than unemployed patients. However, the statistical significance of this association disappeared when adjusted for confounding factors.

Students, patients living with their family, and those who were on treatment for a year or less were significantly more adherent to their medications. In addition, patients who were on treatment for a year and above were significantly more adherent than those who were taking the medications for less than a year. A smaller proportion of patients with comorbidities $(55.1 \%)$ were adherent to their medications when compared with those who had no comorbidities $(72.2 \%)$, although the relationship was not statistically significant.

\section{Discussion}

In the current study, nearly three quarters (71.6\%) of patients were adherent to medications prescribed for the month preceding the data collection period. Adherence rates ranged from $53.1 \%(n=60)$ among patients with a mood disorder to $78.3 \%(n=18)$ for patients with autism. Age, gender, educational status, occupation, living conditions, and duration on treatment were factors that affected patients' medication adherence.

In this study, more than three fifths $(62.8 \%)$ of patients reported that they have never missed an antipsychotic medication dose, while others confessed to at least some form of non-adherence (missing one or more doses or time of taking their medication). More than a quarter $(28.8 \%$ ) of the patients who reported some form of non-adherence had missed eight doses or more and the rest missed varying numbers of doses, ranging from one to seven.

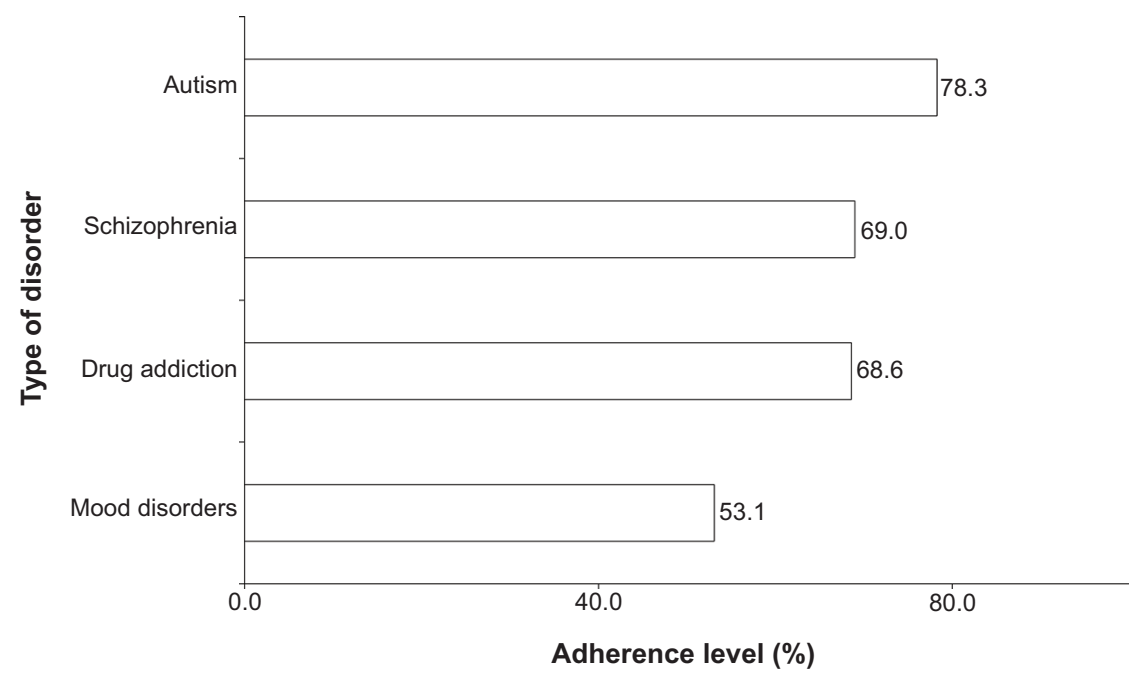

Figure I Adherence among the different types of psychiatric patients. 
Table 2 Predictors of medication non-adherence among the study participants

\begin{tabular}{|c|c|c|c|c|}
\hline $\begin{array}{l}\text { Sociodemographic } \\
\text { characteristics }\end{array}$ & Adherent, n (\%) & Non-adherent, n (\%) & COR $(95 \% \mathrm{Cl})$ & AOR (95\% CI) \\
\hline \multicolumn{5}{|l|}{ Age (years) } \\
\hline $15-25$ & $65(56.0)$ & $5 I(44.0)$ & 1.00 & 1.00 \\
\hline $26-35$ & $81(64.3)$ & $45(35.7)$ & $1.41(1.04-2.37)$ & $\mathrm{I} .64(0.93-\mathrm{I} .86)$ \\
\hline $36-45$ & 69 (71.9) & $27(27.1)$ & $2.01(1.13-3.57)$ & $2.32(1.21-4.43)^{*}$ \\
\hline $46-75$ & $28(56.0)$ & $22(44.0)$ & $1.00(0.5 \mathrm{I}-1.95)$ & $0.86(0.48-1.94)$ \\
\hline \multicolumn{5}{|l|}{ Gender } \\
\hline Male & $103(52.6)$ & $93(47.4)$ & 1.00 & 1.00 \\
\hline Female & $140(73.3)$ & $5 \mathrm{I}(26.7)$ & $2.48(1.62-3.80)$ & $2.34(\mathrm{I} .45-3.74)^{*}$ \\
\hline \multicolumn{5}{|l|}{ Educational status } \\
\hline Illiterate & $58(54.7)$ & $48(45.3)$ & 1.00 & 1.00 \\
\hline Able to read and write ${ }^{* *}$ & $9(56.3)$ & 7 (43.7) & $1.06(0.37-3.07)$ & $1.37(0.39-4.05)$ \\
\hline Primary education & $13(54.2)$ & II (45.8) & $0.98(0.40-2.38)$ & $0.89(0.34-2.29)$ \\
\hline Junior and secondary education & $49(51.6)$ & $46(48.4)$ & $0.88(0.5 \mathrm{I}-\mathrm{I} .53)$ & $0.98(0.3 \mathrm{I}-2.08)$ \\
\hline Tertiary & $114(78.1)$ & $32(21.9)$ & $2.95(1.70-5.10)$ & $2.69(1.46-4.85)^{*}$ \\
\hline \multicolumn{5}{|l|}{ Marital status } \\
\hline Married & $108(83.1)$ & $22(16.9)$ & 1.00 & 1.00 \\
\hline Single & $99(54.1)$ & $84(45.9)$ & $0.24(0.14-0.4 I)$ & $0.33(0.3 \mathrm{I}-1.83)$ \\
\hline Divorced & $9(40.9)$ & $13(59.1)$ & $0.16(0.06-0.43)$ & $0.13(0.12-1.18)$ \\
\hline Widowed & $27(51.9)$ & $25(48.1)$ & $0.22(0.11-0.45)$ & $0.17(0.09-1.26)$ \\
\hline \multicolumn{5}{|l|}{ Job } \\
\hline Housewife/jobless & $58(54.7)$ & $48(45.3)$ & 1.00 & 1.00 \\
\hline Government employee & $30(73.2)$ & II (26.8) & $2.26(1.02-4.10)$ & $1.93(0.94-2.14)$ \\
\hline Farmer & $49(59.0)$ & $34(4 \mid .0)$ & $1.19(0.67-2.13)$ & $1.16(0.37-2.98)$ \\
\hline Merchant & $9(52.9)$ & $8(47.1)$ & $0.93(0.33-2.60)$ & $1.23(0.26-3.91)$ \\
\hline Student & $96(79.3)$ & $25(20.7)$ & $3.18(1.78-5.70)$ & $3.23(1.84-5.91)^{*}$ \\
\hline \multicolumn{5}{|l|}{ Living conditions } \\
\hline Alone & $4 \mathrm{I}(43.6)$ & $53(56.4)$ & 1.00 & 1.00 \\
\hline With family & $202(68.9)$ & 91 (3I.I) & $2.87(1.78-4.62)$ & $2.57(1.66-4.58)^{*}$ \\
\hline \multicolumn{5}{|l|}{ Duration on treatment } \\
\hline Six months to one year & $174(67.7)$ & $83(32.3)$ & $1.85(1.20-2.86)$ & $1.82(1.21-2.84)^{*}$ \\
\hline More than one year & $69(53.1)$ & $61(46.9)$ & 1.00 & \\
\hline \multicolumn{5}{|l|}{ Medical comorbidity } \\
\hline No & $125(72.2)$ & $48(27.8)$ & $2.12(0.98-3.25)$ & $2.14(0.92-3.47)$ \\
\hline Yes & II $8(55.1)$ & $96(44.8)$ & 1.00 & \\
\hline
\end{tabular}

Notes: *Indicates statistically significant association; **respondents with non-formal education. Abbreviations: $\mathrm{Cl}$, confidence interval; $\mathrm{COR}$, crude odds ratio; $\mathrm{AOR}$, adjusted odds ratio.

A study conducted in Jimma, Ethiopia, found that a lower percentage of patients $(52.1 \%)$ reported never missing a medication dose. ${ }^{11}$ The reason for this might be the fact that all the patients in that study were psychotic and their impaired insight would lead to a higher degree of non-adherence.

In our study, patients who took $\geq 80 \%$ of their prescribed medications in the month preceding the data collection were considered to be adherent while those who took $<80 \%$ of their prescribed medications were classified as non-adherent. ${ }^{13,14}$ When gauged by this criterion, the overall average adherence level of the patients was found to be $71.6 \%$. In another study, overall adherence to antipsychotics was found in $43 \%$ of patients and adherence did not differ significantly by medication category. ${ }^{15} \mathrm{~A}$ lower prevalence of drug adherence $(63 \%)$ was reported among Chinese geriatric patients ${ }^{13}$ than in the current study. This could be because adherence tends to be lower in elderly patients. Similarly, a lesser rate of adherence (58.8\%) was reported in a study of adult psychiatric outpatients at Jimma University Specialized Hospital, Ethiopia, ${ }^{16}$ when compared with the present study. The higher rate of adherence in the current study might be due to a difference in the data acquisition methods used, ie, the former study included a review of patient medical records while the current study was restricted to patient interviews. On the other hand, the adherence rate obtained in our study is lower than the general minimum recommended cut-off point $(\geq 80 \%){ }^{13,14}$ This indicates a need to identify strategies that would help to optimize medication adherence in this type of patient population. 
Looking at the adherence rates across different types of disorder, 149 (69\%) of patients with schizophrenia, 60 (53.1\%) of those with a mood disorder, 24 (68.6\%) with drug addiction, and 18 (78.3\%) with autism were adherent. Some studies have reported various levels of adherence (lower, similar, and higher) in schizophrenic patients than in the current study. ${ }^{16}$

The most common reported reasons for missing doses included feeling better after the illness (51.9\%), forgetting (21.2\%), and drug side effects (17.8\%). Many of these reasons were identified by a review of studies conducted in Middle Eastern countries. ${ }^{17}$ In Nigerian psychiatric outpatients, significant independent correlates of poor medication adherence included being unemployed, poor social support, high self-stigma, and perceived spiritual causation of mental illness. ${ }^{16}$ In the study conducted in Jimma, the most common reasons provided for missed medication doses were forgetfulness $(36.2 \%)$, being too busy $(21.0 \%)$, and insufficient information about the medication $(10.0 \%){ }^{11}$

The patients' level of adherence was observed to increase (from $56.0 \%$ to $71.9 \%$ ) with increasing age up to the age of 45 years. Patients in the age range of 26-35 years were found to be significantly more adherent than those aged 15-25 years. A different result was reported by a study conducted among schizophrenic patients in the USA from 1998 to 1999: patients younger than 45 years of age were more likely to be less adherent (46\%) than patients aged 45-64 years $(38 \%)$, who in turn were more likely to be poorly adherent than patients aged 65 years or older $(33 \%) .{ }^{18}$ This difference might reflect differences in population and time. Further, the current study included a number of other types of psychiatric illness in addition to schizophrenia.

Females were more than twice as adherent as males, and patients with tertiary education were also more than twice as adherent as those who were illiterate, and this difference was statistically significant. Although lower proportions of single, divorced, and widowed patients were adherent to their medications, there was no statistically significant relationship between marital status and adherence level. In another study, women tended to be somewhat less adherent than men, although the difference was not statistically significant. ${ }^{15}$

In a study of middle-aged and older outpatients with schizophrenia, cognitive functioning, especially in terms of conceptualization and memory, was the strongest patientrelated predictor of ability to manage medication, over and above the effects of age, gender, educational level, symptom severity, and attitudes toward medication. ${ }^{19}$
Government employees were more adherent than unemployed patients. However, the statistical significance of this association disappeared when adjusted for confounding. Students and patients living with family were more adherent to their medications.

\section{Conclusion}

Adherence of psychiatric patients in this study was found to be suboptimal when compared with the generally recommended cut-off point for good adherence. Adherence was relatively lower in patients with mood disorder or schizophrenia. Age 26-35 years, female gender, tertiary education, and living with family were factors associated with better adherence. Given that feeling better after illness and forgetting were the main reasons reported for missed doses, health professionals in the psychiatric clinic need to counsel patients to take their medications even though they feel better. Family members and care givers must be advised to help patients take their medication as prescribed. It would also be useful to help patients integrate their treatment regimen into their daily routine.

The findings of this study should be interpreted in light of some limitations. The self-report method used to measure medication adherence might substantially overestimate adherence, as it relies on patient response. There is no guarantee of an absence of social desirability and recall bias in patients' responses. Further, this research might not identify all factors (eg, severity and disease symptomatology) contributing to non-adherence, nor accurately measure adherence, which can be addressed by future studies. Despite these limitations, our study identifies issues warranting further indepth investigation regarding medication adherence in psychiatric patients in an Ethiopian referral hospital set-up.

\section{Acknowledgments}

We are very grateful to our study participants and the data collectors. We would also like to extend our thanks to the staff of the psychiatric clinic at Ayder Referral Hospital for their kind cooperation during collection of the data.

\section{Author contributions}

$\mathrm{ZD}, \mathrm{BL}, \mathrm{GT}, \mathrm{BD}, \mathrm{TE}, \mathrm{ZS}$, and MA all contributed to the study design. $\mathrm{ZD}$ and $\mathrm{BL}$ conducted the study, and were supervised in the field by GT and BD. BL wrote the first draft of the manuscript. All authors contributed to interpretation of the study findings. All authors reviewed and approved the final manuscript prior to submission. 


\section{Disclosure}

The authors report no competing interests in this work.

\section{References}

1. American Psychiatric Association. Diagnostic and Statistical Manual of Mental Disorders, 4th Edition, Text Revision (DSM-IV-TR). Washington, DC, USA: American Psychiatric Association; 2000.

2. Fenton WS, Blyler CR, Heinssen RK. Determinants of medication compliance in schizophrenia: empirical and clinical findings. Schizophr Bull. 1997;23(4):637-651.

3. Osterberg L, Blaschke T. Adherence to medication. $N$ Engl J Med. 2005; 353(5):487-497.

4. Taj F, Tanwir M, Aly Z, et al. Factors associated with non-adherence among psychiatric patients at a tertiary care hospital, Karachi, Pakistan: a questionnaire based cross-sectional study. J Pak Med Assoc. 2008;58(8): 432-436.

5. Cramer JA, Rosenheck R. Compliance with medication regimens for mental and physical disorders. Psychiatr Serv. 1998;49(2):196-201.

6. Al-Jumah KA, Qureshi NA. Impact of pharmacist interventions on patients' adherence to antidepressants and patient-reported outcomes: a systematic review. Patient Prefer Adherence. 2012;6:87-100.

7. Mitchell AJ, Selmes T. Why don't patients take their medicine? Reasons and solutions in psychiatry. Adv Psychiatr Treat. 2007;13(5): 336-346.

8. McDonald HP, Garg AX, Haynes RB. Interventions to enhance patient adherence to medication prescriptions: scientific review. JAMA. 2002; 288(22):2868-2879.

9. Magura S, Rosenblum A, Fong C. Factors associated with medication adherence among psychiatric outpatients at substance abuse risk. Open Addict J. 2011;4:58-64.

10. Sun SX, Liu GG, Christensen DB, Fu AZ. Review and analysis of hospitalization costs associated with antipsychotic nonadherence in the treatment of schizophrenia in the United States. Curr Med Res Opin. 2007;23(10):2305-2312.
11. Alene M, Wiese MD, Angamo MT, Bajorek BV, Yesuf EA, Wabe NT. Adherence to medication for the treatment of psychosis: rates and risk factors in an Ethiopian population. BMC Clin Pharmacol. 2012;12:10.

12. Teferra S, Hanlon C, Beyero T, Jacobsson L, Shibre T. Perspectives on reasons for non-adherence to medication in persons with schizophrenia in Ethiopia: a qualitative study of patients, caregivers and health workers. BMC Psychiatry. 2013;13(1):168.

13. Lam PW, Lum CM, Leung MF. Drug non-adherence and associated risk factors among Chinese geriatric patients in Hong Kong. Hong Kong Med J. 2007;13(4):284-292.

14. Khanna R, Pace PF, Mahabaleshwarkar R, Basak RS, Datar M, Banahan BF. Medication adherence among recipients with chronic diseases enrolled in a state Medicaid program. Popul Health Manag. 2012;15(5):253-260.

15. Rittmannsberger H, Pachinger T, Keppelmuller P, Wancata J. Medication adherence among psychotic patients before admission to inpatient treatment. Psychiatr Serv. 2004;55(2):174-179.

16. Adewuya AO, Owoeye OA, Erinfolami AR, et al. Prevalence and correlates of poor medication adherence amongst psychiatric outpatients in southwestern Nigeria. Gen Hosp Psychiatry. 2009;31(2):167-174.

17. Al-Qasem A, Smith F, Clifford S. Adherence to medication among chronic patients in Middle Eastern countries: review of studies. East Mediterr Health J. 2011;17(4):356-363.

18. Valenstein M, Blow FC, Copeland LA, et al. Poor antipsychotic adherence among patients with schizophrenia: medication and patient factors. Schizophr Bull. 2004;30(2):255-264.

19. Jeste SD, Patterson TL, Palmer BW, Dolder CR, Goldman S, Jeste DV Cognitive predictors of medication adherence among middle-aged and older outpatients with schizophrenia. Schizophr Res. 2003;63(1-2): 49-58
Patient Preference and Adherence

\section{Publish your work in this journal}

Patient Preference and Adherence is an international, peer-reviewed, open access journal that focuses on the growing importance of patient preference and adherence throughout the therapeutic continuum. Patient satisfaction, acceptability, quality of life, compliance, persistence and their role in developing new therapeutic modalities and compounds to optimize

\section{Dovepress}

clinical outcomes for existing disease states are major areas of interest for the journal. This journal has been accepted for indexing on PubMed Central. The manuscript management system is completely online and includes a very quick and fair peer-review system, which is all easy to use. Visit http://www. dovepress.com/testimonials.php to read real quotes from published authors. 